\title{
Çoklu Kaynak Gerektiren Parçalarda Kaynak Sırasının Genetik Algoritma Kullanılarak Belirlenmesi
}

\author{
Onur Yurdakul $^{1 *}$, Başar Yavuz ${ }^{2}$ \\ 1* Piri Reis Üniversitesi, Mühendislik Fakültesi, Gemi İnşaatı ve Gemi Makineleri Mühendisliği Bölümü, İstanbul, Türkiye, (ORCID: 0000-0001-8685-6819), \\ oyurdakul@pirireis.edu.tr \\ ${ }^{2}$ Piri Reis Üniversitesi, Mühendislik Fakültesi, Makine Mühendisliği Bölümü, İstanbul, Türkiye (ORCID: 0000-0003-2871-4470), byavuz@pirireis.edu.tr
}

(1st International Conference on Applied Engineering and Natural Sciences ICAENS 2021, November 1-3, 2021)

(DOI: 10.31590/ejosat.1012352)

ATIF/REFERENCE: Yurdakul, O., Yavuz, B. (2021). Çoklu Kaynak Gerektiren Parçalarda Kaynak Sırasının Genetik Algoritma Kullanılarak Belirlenmesi. Avrupa Bilim ve Teknoloji Dergisi, (28), 990-992.

$\ddot{\mathbf{O} z}$

Artan enerji ihtiyacı-kullanımı ve yüksek rekabet şartları firmaları üretim aşamasında iyileştirmeler yapmaya itmektedir. Bu iyileştirmeler ile parça başına düşen maliyetlerin düşürülmesi amaçlanmaktadır. Parça başına düşen maliyetlerin azaltılması yüksek rekabetin olduğu pazarda firmaları bir adım öne çıkaracaktır. Yüksek sayıda üretim yapan firmalar çeşitli bilgisayar destekli imalat programları kullanarak iyileştirmeler yapabilmektedir. Ancak bu tip programlar oldukça maliyetlidir. Özellikle küçük ya da orta ölçekli işletmeler için bu programların satın alınabilmesi çoğu zaman mümkün olmamaktadır. Bu düzeydeki firmaların da pazar içerisinde daha rekabetçi olabilmeleri için teknolojiyi kullanmaları gerekmektedir. Genetik algoritma ile düşük maliyetlerde iyileştirme sonuçlarının alınabilmesi mümkündür. Bu çalışmada da birden çok kaynaklı bölgeye sahip bir parça düşünülmüştür. Bu kaynakların hangi sıra ile yapılacak olması işlem süresini etkilediği için önemlidir. Kaynak sırasının doğru bir şekilde ayarlanması ile işlem daha kısa sürede bitirilebilecektir. Bu tip bir iyileştirme sağlanabilmesi amacıyla kaynaklar arası yolun belirlenmesi sırasında genetik algoritmadan yararlanılmıştır. Genetik algoritma ile üretilen yolun daha iyi bir sonuç verip vermediğinin anlaşılabilmesi amacıyla, kullanıcılar tarafından iki farklı rota belirlenmiştir. Belirlenen iki rota ile genetik algoritma tarafından belirlenen rota karşılaştırılmıştır. Karşılaştırma sonuçlarına göre, genetik algoritma ilk rotadan \% 20.62, ikinci rotadan \% 3.75 daha kısa ve daha verimli bir sonuç vermiştir. Bu tip bir yazılım kullanımı birçok farklı işleme uyarlanabilir. Bu sayede çok çeşitli alanlardaki firmaların süreç iyileştirme aşamalarına yardımcı olabilecektir.

Anahtar Kelimeler: Genetik Algoritma, Kaynak, Rotalama, Süreç İyileştirme, Optimizasyon.

\section{Determination of Welding Sequence in Pieces Requiring Multiple Weldings by Using Genetic Algorithm}

\begin{abstract}
Increasing energy requirements and high competition conditions push companies to make renovations in the production phase. With the advancements to be made, it is aimed to reduce the costs per piece. Reducing the costs per piece will bring companies one step ahead in the highly competitive market. Companies that produce in large quantities can make improvements by using various computer aided manufacturing programs. However, such programs are quite expensive. It is often not possible to purchase these programs, especially for small or medium-sized businesses. Companies at this level also need to use technology in order to be more competitive in the market. With the genetic algorithm, it is possible to obtain better results at low costs. In this study, a piece with more than one welded location is considered. The order in which these weldings will be made is important because it affects the processing time. With the correct setting of the welding sequence, the process will be completed in a shorter time. In order to provide such an improvement, a genetic algorithm was used during the determination of the path between welds. In order to understand whether the path produced by the genetic algorithm gives a better result, two different routes were determined by the users. The two routes determined and the route determined by the genetic algorithm were compared. According to the comparison results, the genetic algorithm yielded $20.62 \%$ shorter and more efficient results than the first route, and $3.75 \%$ shorter than the second route. The use of this type of software is adaptable to many different processes. In this way, it will be able to assist the process improvement stages of companies in a wide variety of fields.
\end{abstract}

Keywords: Genetic Algorithm, Welding, Minimum Path, Process Improvement, Optimization.

* Sorumlu Yazar: oyurdakul@pirireis.edu.tr 


\section{Giriş}

Günümüz artan üretim ihtiyacı parça başına düşen imalat süresinin kısalması ihtiyacını doğurmuştur. Özellikle yüksek adetli üretim yapılan alanlarda görece küçük iyileştirmeler dahi toplam maliyette önemli azalmalar sağlayarak işletmenin karlılı̆̆ını arttırabilmektedir.

Kaynak, tüm alanlarda yaygın olarak kullanılan bir birleştirme yöntemidir. Karmaşı yapıların kaynak ile birleştirilmesi sırasında parça başına işlem süresinin kısaltılması önem arz etmektedir. Bu çalışma kapsamında da önceden belirlenmiş olan birden fazla kaynaklı alana sahip olan bir parça düşünülmüştür. Bu parçanın kaynak yapım sırasında seçilecek yolun kısaltılması amacıyla genetik algoritmadan yararlanılmıştır.

Genetik algoritmalar yaklaşık ya da tam bir çözüm bulmak amacıyla kullanılır ve temel amacının optimizasyonun sağlanması olduğu söylenebilir. Adından da anlaşılacağı üzere genetik algoritmalar, evrimsel biyoloji tekniklerinin mühendislik ya da diğer alanlardaki problemlerin çözümü sırasında kullanılması mantığına dayanmaktadır. Mutasyon, seçilim ya da çaprazlama gibi biyolojik tanımlar çerçevesinde, en optimal çözümü bulmayı amaçlamaktadır [1].

Genetik algoritma pek çok farklı alanda daha iyi çözüm bulunabilmesi amacıyla kullanılmaktadır. Yapılan bir çalışmadan görsel işleme alanında kullanılmıştır. Burada aykırılık haritası oluşturulmuştur. Genetik algoritma ise bu harita üzerinden en iyi olan popülasyonun bulunmasını sağlamıştır [1].

Genetik algoritmanın en büyük avantajı elinizde çözüme yönelik sabit bir formülün olmadığı durumlarda sizi çözüme yaklaştırmasıdır Düşük sayıdaki değişkende çözüme ulaşmak görece kolay iken değişken sayısının çok fazla olduğu durumlarda çözüme ulaşmak zorlaşmaktadır. Daha önce bahsedilen mutasyon, çaprazlama ya da değiştirme gibi kavramlar yardımıyla problemin çözümüne yönelik olan en uygun yola ulaşılabilir. Genetik algoritma ya tam bir sonuç verecek ya da çözüme en yakın sonuca ulaşmamızı sağlayacaktır.

Genetik algoritma dişında farklı algoritmalarda kullanılmaktadır. Yapılan bir çalışmada genetik algoritma ile genelleştirilmiş model seçimi incelenmiştir. Çalışma da hem teorik bir inceleme yapılmış hem de numerik olarak bir çalışma gerçekleştirilmiştir [2]. Wetter ve Wright bu çalışmalarında EnergyPlus [3] adlı yazılımı kullanarak bir simülasyonda gerçekleştirmişlerdir.

Başka bir çalışmada ise genetik algoritma kullanılarak inşaat projelerindeki su depolama alanlarının belirlenmesinde kullanılmıştır. Çalışmada birden çok depolama alanının en efektif şekilde planlanmasında genetik algoritmadan yararlanılarak bir çözüme ulaşılmıştır [4]. Genetik algoritmalarda farklı kodlama mekanizmaları kullanılabilmektedir. Bazı çalışmalarda bu kararın kullanıcı tarafından verilmesinin daha uygun olacağı belirtilmiştir [6] [7].

\section{Materyal ve Metot}

Çalışma kapsamında oluşturulan bir sıralı kaynaklı sac malzeme varlığı kabul edilmiştir. Bu malzeme üzerinde birden fazla sayıda kaynak işlemi yapılan lineer bölgeler tanımlanmıştır (Şekil 1). Bu bölgelerin kaynaklı birleştirme ile birleştirilmesi sırasında hangi sıra ile işlemin gerçekleştirileceği en doğru şekilde belirlenmeye çalışılmıştır.

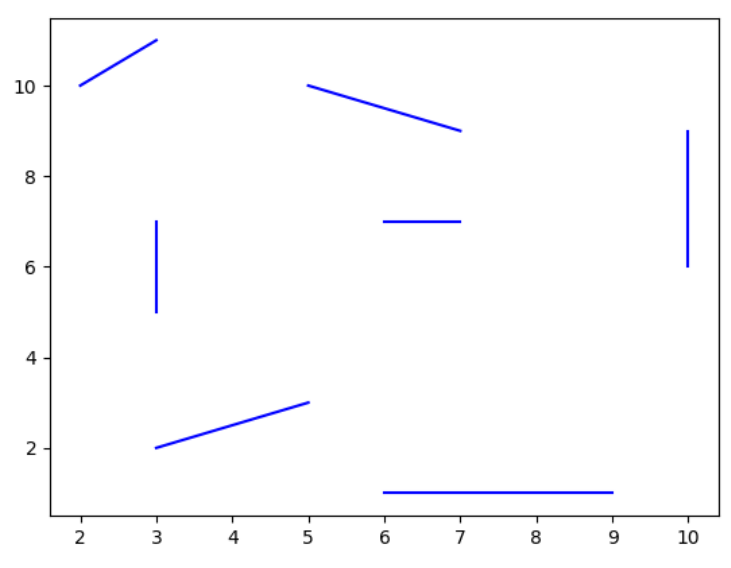

Şekil 1 Kaynakların pozisyonu

Python programlama dilinde yazılan genetik algoritma uygulamasıyla kaynak makinesinin belirlenen kaynak yerlerine en kısa yoldan ulaşması hedeflenmiştir. Genetik algoritma tarafindan oluşturulan yolun optimuma en yakın sonuç olduğunu gösterebilmek için bir karşılaştırma yapıllmıştır. Bu karşılaştırma işleminde aynı kaynak işlemi için 2 farklı kaynak sırası bir kullanıcı tarafından seçilmiş ve kaynaklı bölgeler arasındaki mesafe hesaplanmıştır. İlgili rotalar, olası rota 1 (Şekil 2) ve olası rota 2 (Şekil 3) olmak üzere aşağıda görülebilmektedir. Kırmızı alanlar kaynaklı bölgeler arasındaki boşta gecen mesafeyi vermektedir. $\mathrm{Bu}$ kırmızı yolların toplamının bulunması ile iyileştirme oranı belirlenecektir.

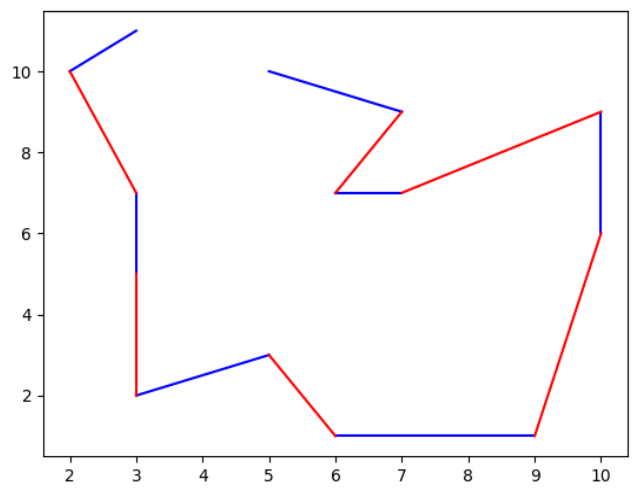

Şekil 2 Olası rotalama 1

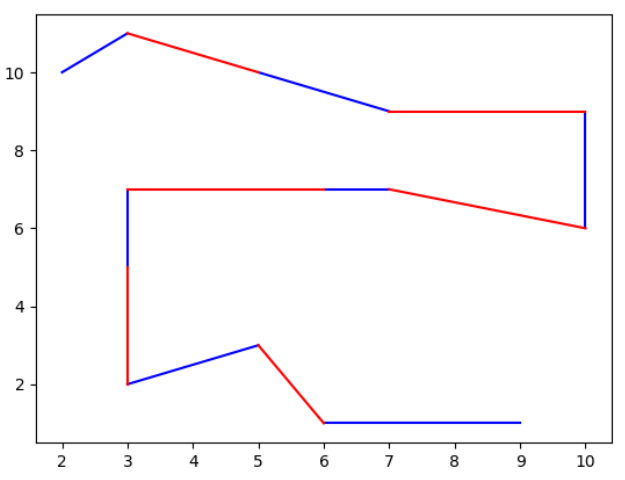

Şekil 3 Olası rotalama 2 
Genetik algoritma ile oluşturulan rota ise optimum rota olarak Şekil 4 'te görülebilmektedir.

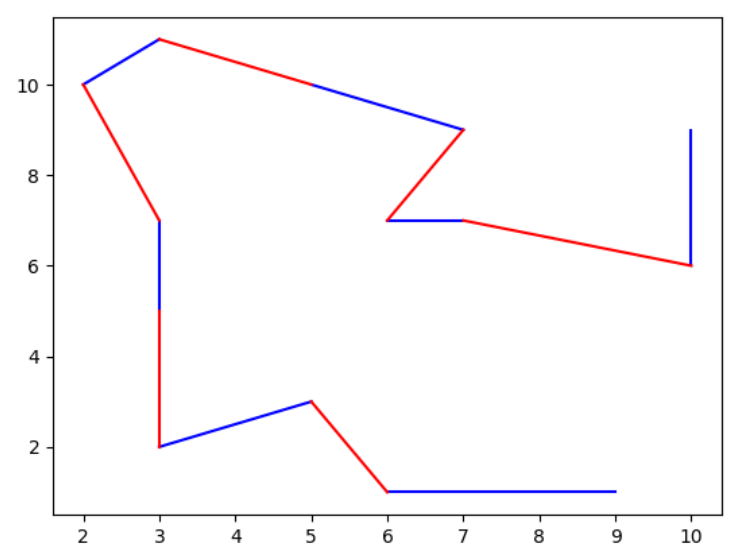

Şekil 4 Optimum rotalama

Elde edilen sonuçlar ve elde edilen iyileştirme oranları Tablo 1 'de verilmiştir.

Tablo 1. İyileştirme değerleri

\begin{tabular}{|c|c|c|}
\hline Rota & Birim Mesafe & İyileştirme (\%) \\
\hline Rota 1 & 19.339 & $\% 20.62$ \\
\hline Rota 2 & 16.634 & $\% 3.75$ \\
\hline Optimum Rota & 16.033 & --- \\
\hline
\end{tabular}

\section{Araştırma Sonuçları ve Tartışma}

Bir kullanıcı tarafından belirlenen kaynaklı birleştirme sırası Şekil 2 ve Şekil 3'de görülebilmektedir. Bu işlemde kaynaklı bölgeler arasında oluşan mesafeler 19.339 ve 16.634 birim olarak hesaplanmıştır.

Elde edilen sonuçlara göre genetik algoritma kullanımıyla en kısa mesafe kat edilerek işlemlerin yapılabilmesi sağlanabilmektedir.

Özellikle üretim sayısının yüksek olduğu durumlarda, parça başına düşen sürenin kısaltılabilmesi toplam maliyet içerisinde önemli bir yer tutacaktır. Bu durumun ise firmalar nezdinde daha rekabetçi bir fiyatlandırma oluşturabilme şansını doğurması kaçınılmazdır.

Daha geniş ölçekte düşünüldüğünde ise düşen parça başı işlem süreleri, enerji kullanım miktarlarında da bir iyileşme olarak karşımıza çıkacaktır.

Bunun yanı sıra genetik algoritma tarafından oluşturulmuş olan kaynaklı birleştirme sırası ise Şekil 4'de görülebilmektedir. Bu sıra ile yapılan kaynak işleminde ise kaynaklı bölgeler arası geçiş mesafesi 16.033 birim olarak hesaplanmaktadır.

Genetik algoritma yardımıyla oluşturulan sonucun alınan yol cinsinden sirasiyla \%20.62 ve \%3.75 daha kısa olduğu sonucu ortaya çıkmaktadır.

\section{Sonuç}

Çalışma kapsamında oluşturulan kaynaklı bir birleştirmede, kaynak sırası oluşturulması sırasında genetik algoritmadan yararlanılmıştır. Kullanılan algoritma sayesinde \%20.62 oranında kaynaklı bölgeler arasındaki geçiş yönünden iyileştirme sağlanmıştır. Bu tip algoritmaların kullanılması ile daha büyük ölçekli projelerde yüksek zaman ve maliyet tasarrufuna gidilebileceği söylenebilmektedir.

\section{Kaynakça}

Crawley, D. B., Lawrie, L. K., Winkelmann, F. C., Buhl, W., Huang, Y., Pedersen, C. O., . . G Glazer, J. (2001). EnergyPlus: creating a new-generation building energy simulation program. Energy and Buildings, 4(33), 443-457.

Eshelman, L., \& Schaffer, J. (1993). Real-coded genetic algorithms and interval-schemata. San Mateo: Morgan Kaufmann Publishers.

Goldberg, D. (1989). Genetic algorithms in search optimization and machine learning. Reading: Addison-Wesley.

Goldberge, D. (1991). Real coded genetic algorithms, virtual alphabets, and blocking. Complex Syst, 5, 139-167.

Hınçal, O., Altan-Sakarya, A., \& Ger, A. (2011). Optimization of Multireservoir Systems. Water Resour Manage, 1465-1487.

Minglun G., Yee-Hong, \& Y. (2001). "Multi-resolution Stereo. Stereo and MultiBaseline Vision (pp. 21-29). IEEE.

Wetter, M., \& Wright, J. (2003). Compaarison of a Generalized Pattern Search and a Genetiv Algorithm Optimization Method. Eight International IBPSA Conference. Eindhoven. 